\title{
EDITORIAL
}

\section{Oral Pathology in India: Current Scenario and Future Directions}

\author{
${ }^{1}$ Sujatha Govindarajan, ${ }^{2}$ Jayanandan Muruganandhan, ${ }^{3} \mathrm{~A}$ Thirumal Raj
}

How to cite this article: Govindarajan S, Muruganandhan J, Raj AT. Oral Pathology in India: Current Scenario and Future Directions. World J Dent 2017;8(6):429.

\section{Source of support: Nil}

Conflict of interest: None

Oral pathology is the specialty of dentistry that deals with the diagnosis of oral diseases through clinicopathological investigations. In India, oral pathology as a specialization seldom makes the cut as a postgraduation of choice. This is primarily due to the fact that most hospitals in India employ general pathologists to diagnose oral diseases, thus restricting the scope of oral pathology to academic and research institutions. In the past, most postgraduates had opted for an academic position in dental institutions as they served as a reliable source of income. Given the past shortage of oral pathologists, it was a viable option.

${ }^{1-3}$ Department of Oral Pathology and Microbiology, Sri Venkateswara Dental College and Hospital, Chennai, Tamil Nadu, India

Corresponding Author: A Thirumal Raj, Department of Oral Pathology and Microbiology, Sri Venkateswara Dental College and Hospital, Chennai, Tamil Nadu, India, Phone: +918122627810, e-mail: thirumalraj666@gmail.com
At present, the number of oral pathologists has significantly outnumbered potential job openings. Further, the scope as a researcher for an oral pathologist in India is a difficult enterprise as most researchers must self-finance their studies. The growing scarcity in academic positions and the lack of research opportunities have forced many oral pathologists to abandon their specialty in order to maintain a full-time clinical practice.

The impending question as of now is whether oral pathology can be a potential career option in the future. Yes, oral pathology could be a successful career option, provided the scope of an oral pathologist is widened. It must be mandated that hospitals employ oral pathologists for diagnosing cases related to the oral cavity. Forensic odontology is an upcoming specialty which could create more job opportunities for an oral pathologist in the legal sector. Thus, it is vital that oral pathologists undergo extensive training in forensic odontology during postgraduation which would provide them with the necessary skills to be a part of the forensic team. Further, given the high prevalence of oral diseases, especially precancer and cancer, in India, it is of utmost importance that the government sets up central funding agencies specifically for oral disease research. The influx of grants would, in turn, create a large-scale job opening while increasing the standard of oral pathology research in India. 